\title{
Identificação de Fácies em Perfis de Poço com Algoritmo Inteligente
}

\author{
Santos, Renata de Sena, UFOPA; Andrade, André José Neves, UFPA.
}

Copyright 2018, SBGf - Sociedade Brasileira de Geofísica

Este texto foi preparado para a apresentação no VIII Simpósio Brasileiro de Geofísica, Salinópolis, 18 a 20 de setembro de 2018. Seu conteúdo foi revisado pelo Comitê Técnico do VIII SimBGf, mas não necessariamente representa a opinião da SBGf ou de seus associados. É proibida a reprodução total ou parcial deste material para propósitos comerciais sem prévia autorização da SBGf.

\section{Resumo}

Desenvolvemos uma solução para identificar fácies litológicas em perfis de poço apresentando dois novos métodos: o Gráfico Vsh-L-K e a rede competitiva angular generalizada. Primeiro codificamos a informação geológica de um poço testemunhado em termos das suas propriedades físicas registradas pelos perfis de porosidade e pela argilosidade calculada pelo perfil de raio gama natural, representados na forma do Gráfico Vsh-L-K. No segundo passo, realizamos a interpretação computacional do Gráfico Vsh-L-K por um algoritmo inteligente construído com base na rede neural competitiva angular generalizada. Os parâmetros operacionais deste algoritmo inteligente são construídos e interpretados com as informações de um poço testemunhado ou em termos do mineral principal, possibilitando a identificação e classificação das camadas presentes em um poço não testemunhado. Esta metodologia é apresentada com dados sintéticos e com perfis de poços testemunhados do Campo de Namorado na Bacia de Campos, Brasil.

\section{Introdução}

O zoneamento do poço ou a interpretação qualitativa do número de fácies em um intervalo identificado como rocha reservatório através da análise visual do comportamento geométrico do perfil, isento de testemunho, é extremamente difícil. O uso do conjunto das características elencadas pelo geólogo, quando da descrição das fácies (WELLER, 1958) não apresenta uma relação direta e determinística com os perfis geofísicos de poço, por não se traduzirem em propriedades físicas registradas pelas ferramentas de perfilagem.

O testemunho têm grande importância para o modelamento e a caracterização de reservatórios, porém sua aplicabilidade é limitada, em função da pequena quantidade de poços testemunhados em um campo petrolífero ou pela impossibilidade tecnológica de execução das operações de testemunhagem, como no caso dos poços de alto ângulo de desvio.

$\mathrm{Na}$ Avaliação de Formação, a partir da associação da informação dos perfis registrados em um poço, foram desenvolvidos alguns métodos gráficos e numéricos visando à produção de uma estimativa realista sobre a litologia das diversas camadas perfiladas no poço (CRAIN, 1986). Um dos métodos mais difundidos é o Gráfico M-N (BURKE; CAMPBELL JR.; SCHIMIDT, 1969), que utiliza os perfis de porosidade (densidade, sônico e porosidade neutrônica) para realizar a estimativa da litologia através da identificação do mineral principal de cada rocha. Em muitas situações práticas, o perfil de densidade pode não ser o registro de melhor qualidade. Nestes casos, se o perfil sônico é de boa qualidade podese utilizar o Gráfico L-K (PANTOJA, 2010), onde o parâmetro $L$ é constituído a partir da associação do perfil de densidade com o perfil sônico e o parâmetro K, a partir da combinação do perfil de porosidade neutrônica com o perfil sônico. No entanto, em semelhança ao Gráfico M$\mathrm{N}$, este gráfico ainda considera a ausência de argilosidade na constituição das rochas para a estimativa do mineral principal.

Desenvolvemos o Gráfico Vsh-L-K, construído a partir da inserção do perfil de argilosidade aos parâmetros $\mathrm{L}$ e K. Esta adição busca produzir uma melhor aproximação da litologia e do posicionamento em profundidade das diversas camadas atravessadas pelo poço. O Gráfico Vsh-L-K produz um mapeamento eficiente da informação qualitativa sobre as fácies descritas na análise de testemunho de um poço testemunhado, em termos das propriedades físicas registradas nos perfis de porosidade adquiridas neste mesmo poço. A incorporação da informação das fácies descritas em um poço testemunhado possibilita que o Gráfico Vsh-L-K realize o transporte desta informação para outros poços não testemunhados do mesmo campo petrolífero.

O Gráfico Vsh-L-K é tridimensional, sujeito à possibilidade da ocorrência de erros de interpretação visual. Assim, para extrair informação e atenuar esses possíveis erros, apresentamos um algoritmo inteligente construído sobre uma rede neural artificial denominada como rede competitiva angular generalizada. O conceito de algoritmo inteligente envolve um conjunto de métodos numéricos, como as redes neurais artificiais, a inferência fuzzy e a computação evolutiva, e são largamente utilizados na engenharia e na geofísica (NIKRAVESH, 2004; HAYKIN, 2005).

A rede competitiva angular generalizada é especializada na identificação de padrões angulares ou agrupamento de pontos no espaço n-dimensional que possuem uma envoltória aproximadamente elipsoidal, realizando assim, a interpretação do Gráfico Vsh-L-K por apresentar esta característica.

A metodologia é apresentada com a utilização de dados sintéticos e avaliada com perfis e análise de testemunho de poços do Campo de Namorado, na Bacia de Campos, Rio de Janeiro, Brasil.

\section{Metodologia}

Gráfico Vsh-L-K

Codificamos as informações mineralógicas de interesse para o zoneamento do poço, presentes nos perfis de densidade, tempo de trânsito e porosidade neutrônica, no Gráfico Vsh-L-K.

Os perfis de porosidade representam um conjunto de perfis utilizados isoladamente ou em associações dois a dois para o cálculo da porosidade. Identificados como: o perfil de densidade, o perfil sônico e o perfil de porosidade neutrônica.

Os perfis de porosidade seguem a equação geral, que podem ser expressa na forma,

$p=\phi p_{w}+V_{s h} p_{s h}+\left(1-V_{s h}-\phi\right) p_{m}$,

o termo $p$ representa a medida registrada em qualquer dos três perfis de porosidade, o termo $\phi p_{w}$ representa a parcela da água para a medida registrada e o termo $V_{s h} p_{s h}$ representa a parcela da argila. O interesse recai especificamente sobre a última parcela da equação 1 , que representa a contribuição da matriz para o valor registrado no perfil e que mostra a possibilidade de 
enfatizar essa informação para a determinação das fácies atravessadas pelo poço.

O Gráfico L-K adota uma combinação particular dos registros do perfil sônico com as medidas do perfil de densidade para definir o parâmetro $L$ (equação 2). A mesma interpretação do gráfico sônico-neutrônico leva a definição do parâmetro K (equação 3). A substituição dos valores tabelados (tabela 1) das propriedades físicas mensuradas pelas ferramentas de porosidade para os principais minerais na constituição das rochas sedimentares resulta em pares ordenados $(L, K)$ que definem os pontos de referência, dado por:

$L=\frac{\rho_{m}-\rho_{w}}{\left(\Delta t_{w}-\Delta t_{m}\right)} 100$

$K=\frac{\phi_{N w}-\phi_{N m}}{\left(\Delta t_{w}-\Delta t_{m}\right)} 100$

os termos $\rho_{m}, \rho_{w}$ significam, respectivamente, densidade da matriz e densidade da água doce. E os termos $\phi_{N w}$, $\phi_{N m}$ são as porosidade neutrônica da água doce e a porosidade neutrônica da matriz, enquanto $\Delta t_{w}$ e $\Delta t_{m}$ são os tempo de trânsito na água doce e o tempo de trânsito na matriz. A constante multiplicativa em ambas as equações é apenas um fator de escala.

Substituindo nas equações 2 e 3 os valores das propriedades da matriz pelos valores registrados nos correspondentes perfis para cada profundidade, obtêmse as coordenadas de cada ponto a ser classificado no Gráfico L-K. Admite-se, que pontos de uma mesma litologia se agrupem nas proximidades do ponto de referência determinado pelas propriedades físicas do mineral principal desta litologia de forma elíptica, necessitando, por tanto, do conceito de padrão angular para promover a classificação litológica.

Tabela 1 - Valores de L e K para alguns Minerais.

\begin{tabular}{lccccc}
\hline Mineral & Densidade & $\begin{array}{c}\text { Porosidade } \\
\text { neutrônica }\end{array}$ & $\begin{array}{c}\text { Tempo de } \\
\text { trânsito }\end{array}$ & $\mathbf{L}$ & $\mathbf{K}$ \\
\hline Quartzo & 2,65 & $-0,04$ & 55,5 & 0,78 & 1,24 \\
Calcita & 2,71 & 0,00 & 47,0 & 0,70 & 1,20 \\
Dolomita & 2,86 & 0,07 & 43,5 & 0,64 & 1,28 \\
Ortoclásio & 2,55 & $-0,05$ & 66,5 & 0,86 & 1,26 \\
Albita & 2,62 & $-0,04$ & 46,4 & 0,73 & 1,14 \\
Anidrita & 2,96 & 0,02 & 51,8 & 0,71 & 1,43 \\
\hline Argilomineral & & & & & \\
\hline Caulinita & 2,42 & 0,36 & 103,8 & 0,75 & 1,66 \\
Ilita & 2,53 & 0,25 & 97,2 & 0,82 & 1,66 \\
Esmectita & 2,12 & 0,44 & 121,8 & 0,83 & 1,66 \\
\hline
\end{tabular}

Fonte: Adaptado de Pantoja, 2010.

A argilosidade $\left(V_{s h}\right)$ deve ser obtida de forma independente dos perfis de porosidade. Adotamos o perfil de raios gama natural para o cálculo da argilosidade, expresso por:

$V_{s h}=\frac{G R-G R_{\min }}{G R_{\max }-G R_{\min }}$,

onde $G R$ é o valor do perfil de raios gama natural na profundidade onde deseja-se avaliar a argilosidade, o $G R_{\text {min }}$ representa o valor do perfil de raios gama natural assumido para a rocha limpa e $G R_{\max }$ é o valor assumido para o folhelho.

O Gráfico Vsh-L-K é construído para um conjunto de poços testemunhados de um campo petrolífero. Nas rochas reservatório é pouco provável a constituição da matriz por um único mineral e a argilosidade apresenta grandes variações de volume, de associações de argilominerais e de formas de ocorrência. Assim, o Gráfico Vsh-L-K somente pode ser utilizado para o mapeamento das fácies previamente identificadas no conjunto de poços testemunhados.

As coordenadas de um ponto de referência no Gráfico Vsh-L-K, o centro de gravidade representativo de uma fácies, são obtidas pela média aritmética dos valores de $V_{s h}$, L e K calculados no intervalo de profundidades de ocorrência da fácies, como definido na análise de testemunho.

No entanto, a interpretação visual deste gráfico, na maioria dos casos é complexa. Por isso, apresenta-se uma rede neural competitiva capaz de interpretar o Gráfico Vsh-L-K de modo a localizar a informação sobre cada uma das fácies no intervalo de rocha reservatório do perfil e classificá-las de um modo geologicamente realista.

\section{Algoritmos Inteligentes}

As redes neurais artificiais, a partir dos algoritmos inteligentes, têm a capacidade de operar e encontrar uma solução aceitável mesmo quando apresentam condições severas de imprecisão, incerteza e parcialidade da informação, podendo ser modificadas ou adaptadas para restringir as similaridades nos dados de entrada à solução de problemas específicos.

A partir da rede neural competitiva (KOHONEN, 1989) e da rede competitiva angular (BARROS; ANDRADE, 2013) desenvolvemos a rede competitiva angular generalizada. A rede competitiva angular generalizada é uma ampliação dos conceitos e critérios de treinamento definidos na rede competitiva angular para o espaço $n$ dimensional. Sua arquitetura permite que o número de neurônios da camada de entrada defina a dimensão do espaço dos dados de entrada (Figura 1). O número de neurônios competitivos indica o número de classes previamente identificadas e nas quais se deseja classificar os dados de entrada a partir de um treinamento não supervisionado.

Os dados de entrada ou os pontos no espaço ndimensional a serem classificados são associados a vetores posição $\left(x_{i}\right)$ e para cada vetor é calculado o seu vetor unitário $\left(\bar{x}_{\imath}\right)$, ou

$x_{i}=\left(x_{1}, x_{2}, x_{3}, \cdots, x_{n}\right) \rightarrow \bar{x}_{l}=\frac{x_{i}}{\left|x_{i}\right|}, \quad i=1,2 \ldots N$

onde $\mathrm{N}$ é o número de pontos no conjunto de dados de entrada. O termo $\left|x_{i}\right|$ representa o modulo de um vetor posição.

Cada neurônio competitivo representa uma classe das $M$ classes previamente estabelecida ou um ponto de referência no espaço $n$-dimensional. $O$ vetor de pesos sinápticos $\left(\overline{w_{J}}\right)$ que liga cada neurônio competitivo à camada de entrada é constituído pelos componentes associados às coordenadas do unitário do vetor posição $\left(w_{j}\right)$ correspondentes ao ponto de referência $j$, ou

$w_{j}=\left(w_{1}, w_{2}, w_{3}, \cdots, w_{n}\right) \rightarrow \overline{w_{J}}=\frac{w_{j}}{\left|w_{j}\right|}, \quad j=1,2, \ldots M$

O potencial de entrada $\left(u_{j}\right)$ de cada neurônio competitivo é tomado como o produto interno entre o vetor de entrada e cada um dos vetores associados aos neurônios competitivos (pesos sinápticos), ou

$u_{i}=\bar{x}_{l} \cdot \overline{w_{l}}=\left|\bar{x}_{l}\right|\left|\overline{w_{l}}\right| \cos \theta=\cos \theta$,

em que $\theta$ é o ângulo entre os vetores de entrada e o vetor representativo de cada neurônio competitivo.

O sinal de saída $(y)$ de um neurônio competitivo angular resulta da avaliação da função de ativação $(f)$ pelo o potencial de entrada, ou $y_{j}=f\left(u_{j}\right)$, tomada como uma 
função do tipo caixa (equação 8). Os valores das constantes $a$ e $b$ definem os limites de classificação.

$$
f\left(u_{j}\right)=\left\{\begin{array}{lr}
1, & a \leq u_{j} \leq b \\
1, & -a \geq u_{j} \geq-b \\
0, & \text { outros casos }
\end{array}\right.
$$

A função de ativação busca a proximidade angular entre pontos no plano, tem-se que o ângulo formado pelos seus vetores posição é próximo de zero, ou o seu cosseno próximo de um. Logo, na competição do neurônio vencedor, ganha o detentor do maior valor para o cosseno do ângulo, ou seja, o maior produto interno.

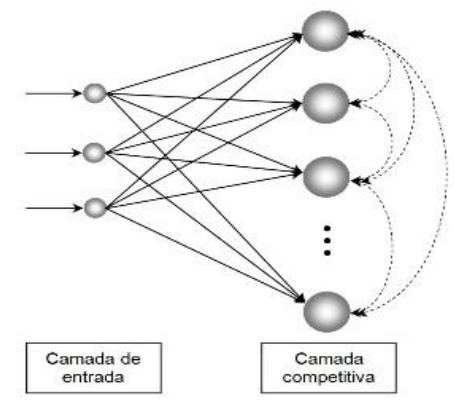

Figura 1. Arquitetura da rede competitiva angular generalizada para a classificação de pontos distribuídos no espaço tridimensional.

\section{Resultados}

\section{Resultados em dados sintéticos}

Compulsoriamente admitimos as seguintes premissas: i) - Gráfico Vsh-L-K é capaz de reter e transportar as características físicas de cada uma das fácies identificadas em um poço testemunhado para outros poços na sua vizinhança; ii) as propriedades físicas de cada uma das fácies representam as diferenças geológicas estabelecidas nas análises de testemunhos; iii) a rede competitiva angular generalizada é capaz de capturar as características físicas explicitadas no Gráfico Vsh-L-K e transportá-las para a interpretação de poços não testemunhados.

O modelo para a geração dos perfis sintéticos segue a equação 1 para os perfis de porosidade e a equação 4 , para o perfil de raio gama natural. As propriedades petrofísicas, porosidade $(\phi)$, argilosidade $\left(\mathrm{V}_{\mathrm{sh}}\right)$ são tomadas como valores aleatórios nos intervalos $[0,05$ $0,20]$ e $[0,00,10]$ respectivamente.

O poço I (Figura 2) mostra um conjunto de perfis sintéticos para um poço testemunhado para um intervalo perfilado de profundidades que representa o topo de uma camada selante $(1.000 \mathrm{~m})$ a base de uma camada reservatório $(1.012 \mathrm{~m})$.

O perfil de raios gama natural $(R G)$, o perfil de densidade (Rhob), o perfil de porosidade neutrônica (Phin) e o perfil sônico (Delt), são mostrados na Figura 2 ( $A, B, C$ e D, respectivamente). A Figura 2-E mostra o zoneamento do intervalo perfilado do poço I, produzidas na análise de testemunho, com as seguintes fácies: a) folhelho; b) arenito grosseiro com matriz argilosa e marcas de retrabalhamento; c) arenito médio, bem selecionado, com marcas de ondas; d) arenito fino, maciço, com laminas de argila.

A partir dos perfis de porosidade do poço I e com a aplicação das equações 2, 3 e 4 obtêm-se os pontos no Gráfico Vsh-L-K para o poço testemunhado.

A Figura 3 mostra o Gráfico Vsh-L-K para o poço I, destacando as fácies de interesse. Observa-se, que a determinação dos centros das fácies poderia ser obtida, mesmo sem a análise de testemunho.
Uma vez construído o Gráfico Vsh-L-K contendo os pontos de referência (quadrados pretos) das fácies de interesse, procede-se ao transporte da informação geológica adquirida no poço testemunhado para os outros poços não testemunhados na sua vizinhança.

É critério do petrofísico, atendendo as condições geológicas locais (estruturais e estratigráficas), estabelecer a quais poços não testemunhados são realistas o procedimento de transporte da informação geológica contida no Gráfico Vsh-L-K.

A Figura 4 mostra os perfis sintéticos para um poço não testemunhado (poço II) considerado como perfurado nas vizinhanças do poço de referência (poço I). A Figura 4-A mostra o perfil de raio gama natural. O perfil de densidade (Rhob) está na Figura 4-B; o perfil de porosidade neutrônica (Phin), na Figura 4-C e o perfil sônico (Delt), na Figura 4-D. A Figura 4-E mostra a distribuição em profundidade das fácies adotadas no modelamento dos perfis do poço II. Observa-se neste intervalo do poço II a ocorrência de duas fácies não descritas no poço I. Assim, na descrição das fácies do poço II, têm-se: a) folhelho; b) arenito grosseiro com matriz argilosa e marcas de retrabalhamento; c) arenito médio, bem selecionado, com marcas de ondas; d) arenito fino, maciço, com laminas de argila; e) marga; f) calcário altamente dolomitizado. Enfatiza-se que a informação das fácies presentes no poço II é utilizada apenas como validação da interpretação do Gráfico Vsh-L-K realizada pela rede competitiva angular generalizada.

O transporte da informação geológica adquirida no poço testemunhado ocorre com o lançamento dos pontos calculados pelas equações 2, 3 e 4 com os perfis do poço não testemunhado no Gráfico Vsh-L-K, como apresentado na Figura 5. As cruzes em vermelho são os pontos calculados com os perfis do poço II.

A interpretação do Gráfico Vsh-L-K é realizada pela rede competitiva angular generalizada e sua camada de entrada é constituída por três neurônios de entrada, tal que cada um recebe uma das coordenadas de cada ponto do Gráfico Vsh-L-K.

Na prática é rara a possibilidade de identificação das fácies de interesse através da interpretação visual de um determinado intervalo nos perfis do poço não testemunhado. Com uma escolha arbitrária de um intervalo, como na perfilagem durante a perfuração (LWD), pode ocorrer a presença de fácies não descritas no poço testemunhado. Como cada neurônio competitivo representa uma fácies (classe), a camada competitiva é formada por um número de neurônios competitivos igual ao número de fácies descritas no poço testemunhado mais os seis minerais mostrados na Tabela 1. Para os minerais a coordenada representativa da argilosidade é tomada como nula.

A interpretação visual do Gráfico Vsh-L-K contendo os pontos calculados com os perfis registrados no poço II permite associá-los aos pontos de referência (quadrados pretos) das fácies descritas no poço I. Ainda, permite a interpretação da ocorrência no poço II de duas novas fácies (agrupamentos de pontos) não descritas no poço I.

Para a interpretação do Gráfico Vsh-L-K (Figura 5), a camada competitiva é constituída por dez neurônios. Em cada neurônio competitivo é avaliada a função de ativação com o potencial de entrada, mostrado na equação 7. A disposição dos vetores envolvidos no Gráfico Vsh-L-K leva a simplificação da função de ativação, adotando-se os valores para $a=0,95$ e $b=$ 1,00, definidos de forma empírica, na forma: 
$f\left(u_{j}\right)=\left\{\begin{array}{lr}1, & a \leq u_{j} \leq b \\ 0, & \text { outros casos }\end{array}\right.$.

A Figura 6 mostra os resultados da operação da rede competitiva angular generalizada. A Figura 6-A mostra o perfil de raios gama natural do poço II. Na Figura 6-B são apresentados os resultados da identificação das fácies e na Figura 6-C a análise de testemunho, como mostrada na Figura 4-E.

Observa-se, na maioria dos casos, que a relação angular promove uma melhor classificação dos pontos no Gráfico Vsh-L-K, que a relação de distância Euclidiana, pois problemas relacionados às calibrações das ferramentas, às correções das medidas e a ocorrência de ruído, muitas das vezes alteram estas relações de distância, que são normalmente admitidas nas interpretações dos gráficos de identificação litológica construídos dos perfis de porosidade.

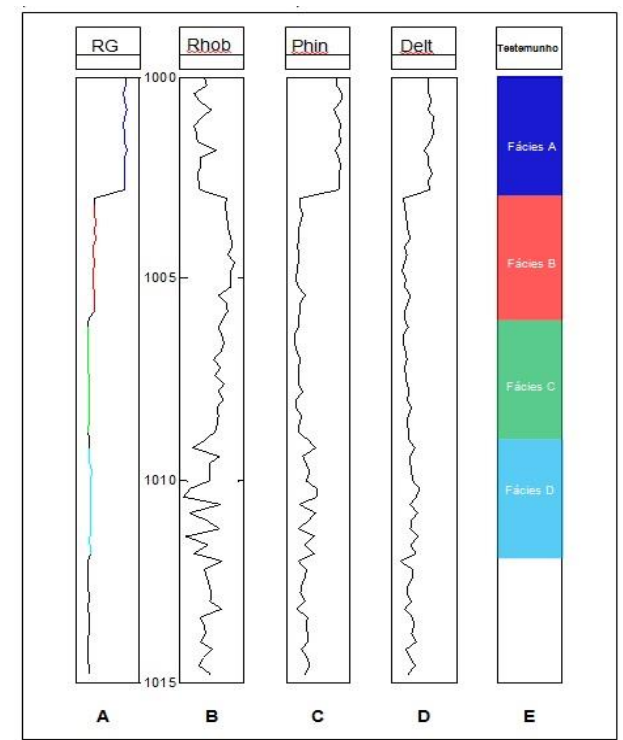

Figura 2 - Perfis com a análise de testemunho do poço I. A) $R G$ é o perfil de raios gama natural; B) Rhob é o perfil de densidade; C) Phin é o perfil de porosidade neutrônica; D) Delt é o perfil sônico; E)Testemunho.

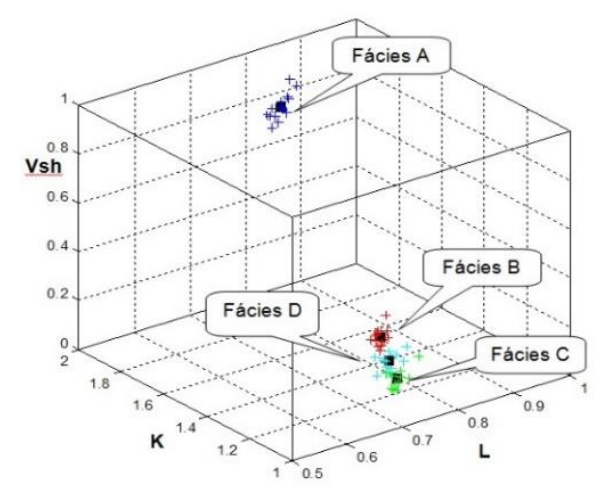

Figura 3 - Gráfico Vsh-L-K para o poço I. Os quadrados em preto representam os pontos de referência indicativos das fácies.

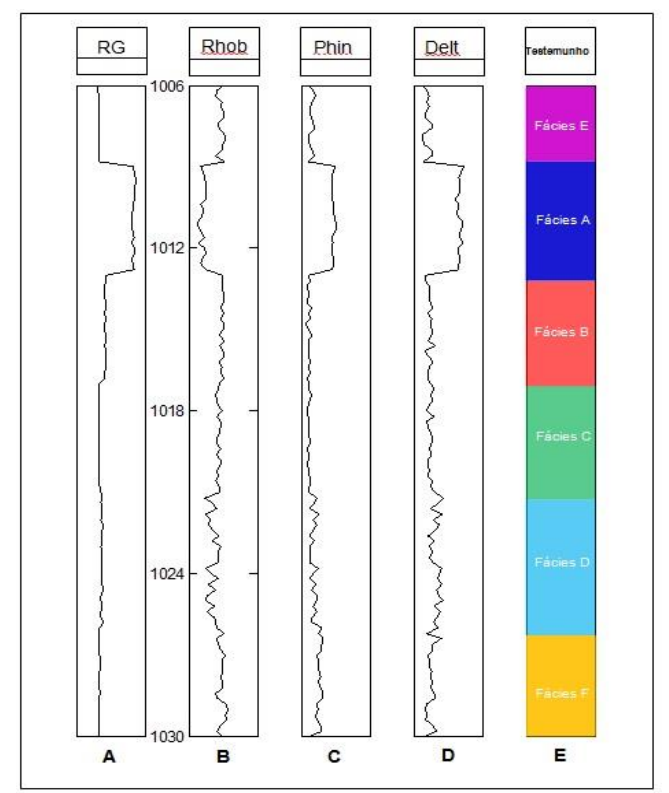

Figura 4 - Perfis com a análise de testemunho do poço II. A) $R G$ é o perfil de raios gama natural; B) Rhob é o perfil de densidade; C) Phin é o perfil de porosidade neutrônica; D) Delt é o perfil sônico; E) Testemunho.

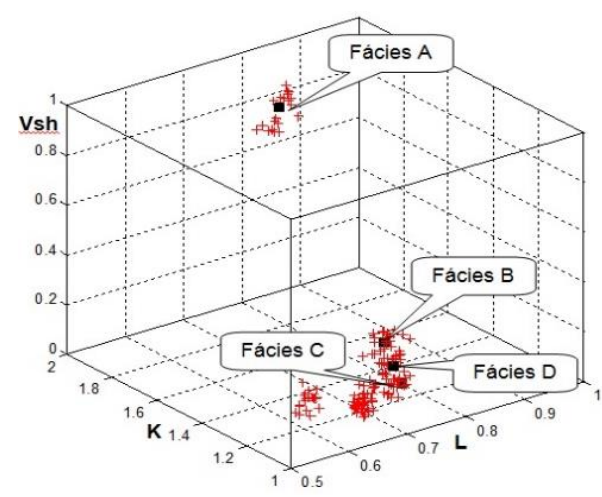

Figura 5- Gráfico Vsh-L-K para o poço II. Os quadrados em preto representam os pontos de referência indicativos das fácies.

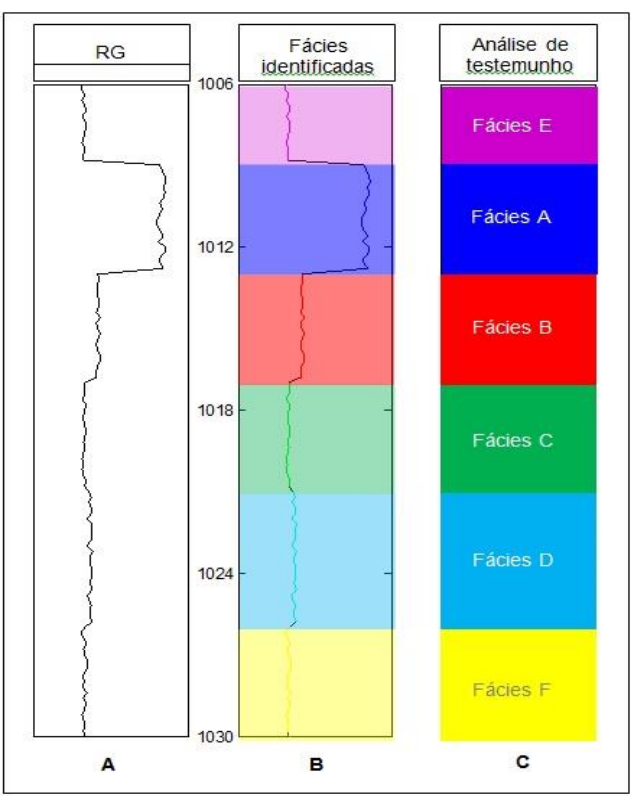

Figura 6 - Fácies identificadas no poço II. A) Perfil de raios gama natural; B) Fácies identificadas; C) Análise de testemunho contendo 6 fácies. 


\section{Resultados em Dados Reais}

Consideramos dois poços testemunhados e relativamente próximos, perfurados no campo de Namorado na Bacia de Campos, Rio de Janeiro, Brasil. A utilização dos poços testemunhados tem como objetivo validar a codificação e o transporte da informação geológica possibilitados pelo Gráfico Vsh-L-K e avaliar a sua interpretação através do processamento do algoritmo inteligente apresentado em função da performance da rede competitiva angular generalizada.

O poço RI (Figura 7) será utilizado como referência para a identificação das fácies. Descrito, segundo a Petrobras, como: fácies $A$, interlaminado siltito e folhelho com níveis de marga bioturbado; e fácies $B$, arenito médio maciço bem graduado.

A Figura 7-A mostra o perfil de raios gama natural, a Figura 7-B mostra o perfil de densidade e as Figuras 7-C e 7-D mostram os perfis de porosidade neutrônica e sônico, respectivamente. $\mathrm{Na}$ Figura 7-E está o zoneamento deste intervalo de profundidades do poço RI construído segundo a descrição do testemunho.

A Figura 8 mostra o Gráfico Vsh-L-K construído a partir dos perfis do poço RI. Na medida que escolheu-se uma fácie selante e uma fácie reservatório como as fácies de interesse, elas formam agrupamentos bastante distintos no Gráfico Vsh-L-K. As cruzes azuis representam a fácies $A$ e as cruzes vermelhas mostram o agrupamento de pontos da fácies $B$. Os quadrados pretos representam os centos de gravidade aproximados de cada um dos agrupamentos.

O poço RII será utilizado como o poço de teste e serão procuradas as fácies de referência identificadas no poço RI. As fácies identificadas no testemunho do poço RII são: fácies $A$, interlaminado siltito argiloso, marga $e$ folhelho bioturbado; e fácies $B$, arenito médio graduado. Comparando as descrições das fácies, dos poços RI e RII, é visível a semelhança em termos de mineralogia e efeitos de diagenéticos nas camadas dos dois poços.

A Figura 9 mostra o conjunto de perfis mensurados no intervalo de profundidades de 3030 a 3070 metros. A Figura 9-A mostra o perfil de raios gama natural, a Figura 9-B mostra o perfil de densidade e as Figuras 9-C e 9-D mostram os perfis de porosidade neutrônica e sônico, respectivamente. Na Figura 9-E está o zoneamento deste intervalo de profundidades do poço RII construído segundo suas fácies $A$ e $B$.

O Gráfico Vsh-L-K para o poço RII é apresentado na Figura 10. As cruzes azuis representam os pontos calculados com os perfis no intervalo de profundidades mostrado na Figura 7. Observa-se a dificuldade da interpretação visual da Figura 10 em função dos pontos representativos das fácies de referência, que estão mostrados na forma dos quadrados pretos. No entanto, observa-se alguma similaridade entre as fácies descritas nos dois poços. A rede neural competitiva angular generalizada é construída a partir dos pesos sinápticos definidos pelas coordenadas dos pontos de referência das fácies e dos pontos fixos do Gráfico L-K. A semelhança notada na descrição geológica das fácies pode ser estendida à semelhança entre as propriedades físicas.

A associação das fácies às profundidades das correspondentes camadas é apresentada na Figura 11, que mostra na Figura 11-A o perfil de raios gama natural do poço RII como referência. Na figura 11-B é mostrado o zoneamento do poço RII produzido pela rede competitiva angular generalizada quando interpreta o Gráfico Vsh-L-K do poço RII.

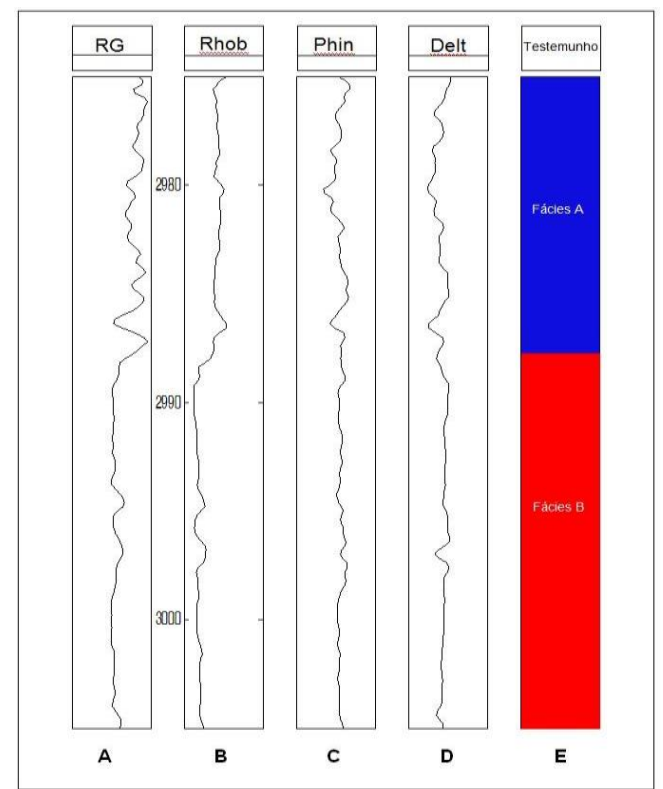

Figura 7 - Perfis com a análise de testemunho do poço RI. A) RG é o perfil de raios gama natural; B) Rhob é o perfil de densidade; C) Phin é o perfil de porosidade neutrônica; D) Delt é o perfil sônico; E) Testemunho.

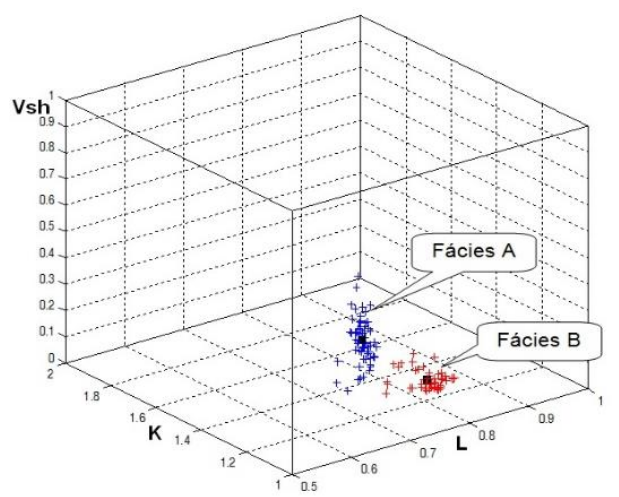

Figura 8- Gráfico Vsh-L-K para o poço RI. Os quadrados em preto representam os pontos de referência indicativos das fácies.

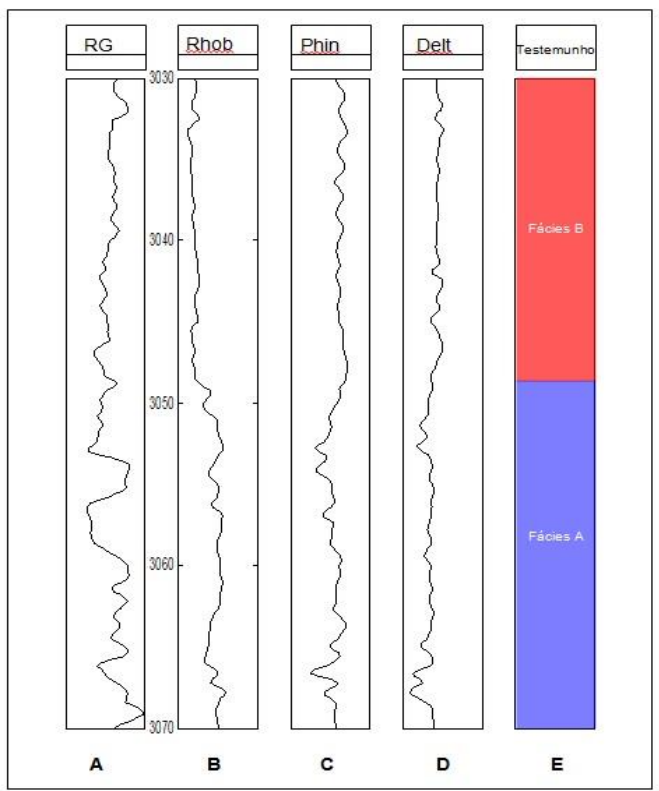

Figura 9 - Perfis com a análise de testemunho do poço RII. A) RG é o perfil de raios gama natural; B) Rhob é o 
perfil de densidade; C) Phin é o perfil de porosidade neutrônica; D) Delt é o perfil sônico; E) Testemunho.

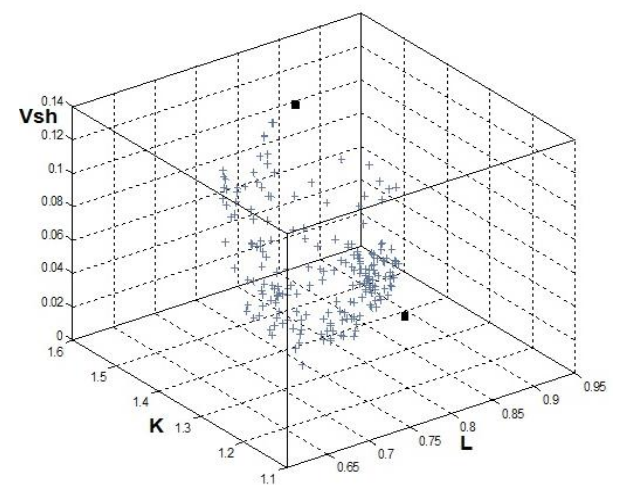

Figura 10 - Gráfico Vsh-L-K para o poço RII. Os quadrados em preto representam os pontos de referência indicativos das fácies.

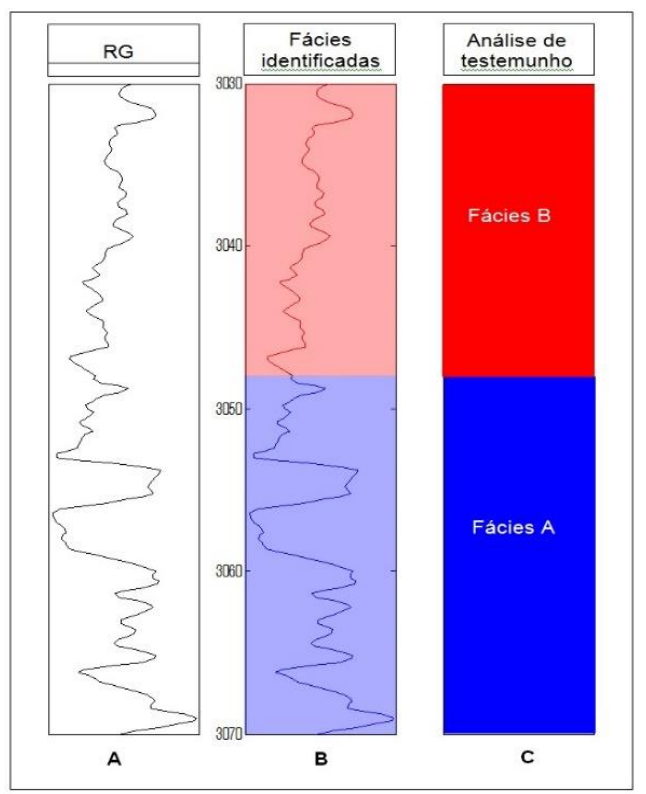

Figura 11 - Fácies identificadas no poço RII. A) Perfil de raios gama natural; $B$ ) Fácies identificadas; C) Análise de testemunho.

\section{Conclusões}

A identificação de fácies em poços não testemunhados e utilizando apenas os dados da perfilagem de poço é um problema de extrema complexidade, com grande ambiguidade e em muitos casos pode não apresentar uma solução realista. A metodologia aqui apresentada baseou-se em duas premissas: A primeira considera que o Gráfico Vsh-L-K representa uma eficiente codificação da informação qualitativa geológica, ou a descrição das fácies em um poço testemunhado em termos das propriedades físicas mensuradas nos perfis geofísicos. $\mathrm{Na}$ segunda premissa, toma-se que a correspondência definida no Gráfico Vsh-L-K pode ser transportada para poços não testemunhados. Nos resultados pode-se avaliar a realidade destas premissas.

Enquanto se mostrou as qualidades do Gráfico Vsh-L-K tem-se que considerar o fundamental papel exercido pela rede neural competitiva angular generalizada para a interpretação ou a extração da informação contida no Gráfico Vsh-L-K em termos de conhecimento das fácies sedimentares presentes no poço não testemunhado.
A rede neural competitiva angular generalizada apresentada neste trabalho possui um amplo espectro de aplicações não se restringindo ao exemplo aqui discutido. Para este problema de identificação de fácies em perfis a solução apresentada neste trabalho é extremamente realista, não implicando, no entanto, que se tenha alcançado a sua solução definitiva. Propõe-se a sua extensão para o caso $n$-dimensional envolvendo um maior conteúdo de informação geológica presente em um maior número de perfis utilizados para a identificação de fácies.

\section{Agradecimentos}

Agradecimentos à Capes, a Petrobras, ao CPGF-UFPA, ao laboratório de Poço (PROLOG), e à UFOPA.

\section{Referências}

BARROS, C.; ANDRADE, A. Determination of water saturation by intelligent algorithm. Journal of Petroleum Science and Engineering. Volume 102, February 2013, Pages 47-56.

BURKE, J. A.; CAMPBELL JR, R.L.; SCHIMIDT, A.W. The Litho-porosity cross plot: a method of determining rock characteristics for computation of log data. In: SPE ILLINOIS BASIN REGIONAL MEETING, 1969, Evansville, Indiana. Illinois Basin. Evansville, Indiana: Society of Petroleum Engineers, 1969. p. 187- 198.

CRAIN, E. R. The Log analysis handbook: quantitative log analysis methods, Tulsa: Pennwell Books, 1986.

HAYKIN, S. Redes neurais: princípios e práticas. São Paulo: Bookman, 2001.

KOHONEN, T. Self-organization and associative memory. Berlin, Springer- Verlag, 1989. 312 p.

NIKRAVESH, M. Soft computed based computational intelligent for reservoir characterization. Expert Systems with Applications, v. 26, p.19-38.2004.

PANTOJA, M.G.P. Zoneamento faciológico de perfis de poço. Monografia, UFPA, Belém, Pará. 2010.

WELLER, J.M. Stratigraphic facies differentiation and nomenclature. Am. Ass. Petrol. Geologists, Bull., 40, p.17-50.1958. 